\title{
A correlative study of autonomic neuropathy and gall bladder volume in patients with diabetes mellitus
}

\author{
Kotresh Doddamane ${ }^{1}$, Adarsh V B ${ }^{2}$, Deepak Kumar $\mathbf{V}^{3}$ \\ ${ }^{1}$ Dr. Kotresh Doddamane, Associate Professor, Department of General Medicine, Gadag Institute of Medical Sciences, \\ Gadag, Karnataka, India, ${ }^{2}$ Dr. Adarsh V B, Assistant Professor, Department of General Medicine, ESIC Medical College, \\ Gulbarga, Karnataka,India, ${ }^{3}$ Dr. Deepak Kumar V, Assistant Professor, Department of General Medicine, Shantaram \\ Medical College, Nandyal, India.
}

Address for Correspondence: Dr. Kotresh Doddamane, E-mail: kotresh_doc@yahoo.co.in

\begin{abstract}
Introduction: Diabetic autonomic neuropathy (DAN) is among the least recognized and understood complication of diabetes despite its significant negative impact on survival and quality of life in people with diabetes. Various studies showed that there is increased prevalence of gall bladder diseases like gall stones in patients with diabetes. Methods: This study was done to evaluate gall bladder volume in diabetics, it's comparison with a control group, and correlation of gallbladder volume in diabetics with various parameters like autonomic neuropathy, age, sex, body mass index, hyperlipidaemia and duration of diabetes. 100 proven diabetic patients and 100 healthy controls were recruited for the study. A detailed history and physical examination findings were recorded. Autonomic neuropathy was determined by using simple noninvasive bedside tests. Fasting gallbladder volume was calculated using ellipsoid formula by ultrasonography. Results: The mean fasting gallbladder volume in diabetics was $23.1 \pm 7.3 \mathrm{ml}$ as compared to controls i.e 13.0 $\pm 3.4 \mathrm{ml}$. Conclusion: When type 2 diabetics were sub grouped according to the presence of autonomic neuropathy, higher gallbladder volumes were seen in patients with autonomic neuropathy.
\end{abstract}

Key words: Gall Bladder volume, Autonomic neuropathy, Diabetes mellitus, Ultrasonography, Gall stone.

\section{Introduction}

Diabetes mellitus is a group of metabolic disorders characterized by hyperglycemia resulting from defects in insulin secretion, insulin action or both. The chronic hyperglycemia of diabetes is associated with long term damage/dysfunction and failure of various organs, especially the eyes, kidneys, nerves, heart and blood vessels. Diabetic autonomic neuropathy (DAN) is among the least recognized and understood complication of diabetes despite its significant negative impact on survival and quality of life in people with diabetes [1]. Various studies point towards the increased prevalence of gall bladder diseases like gall stones in diabetics. This has been attributed to cholecystomegaly \& impaired gall bladder contraction, mainly due to autonomic neuropathy seen in diabetics [2]. Among various microvascular complications like

Manuscript received $24^{\text {th }}$ July 2016

Reviewed: $8^{\text {th }}$ August 2016

Author Corrected: $20^{\text {th }}$ August 2016

Accepted for Publication $31^{\text {st }}$ August 2016 retinopathy, nephropathy and neuropathy, autonomic neuropathy although a well recognized complication, has been given less attention. In autonomic neuropathy involvement of both parasympathetic and sympathetic chains leads to various manifestations involving various organs in the body. Autonomic manifestations in the gastrointestinal tract includes gastropathies, nocturnal diarrhoea, esophageal dysmotility, constipation and gallbladder dysfunction. Gall bladder involvement in diabetic autonomic neuropathy is in the form of high incidence of gall stones and a significant increase in gall bladder volume with poor concentration and poor visualization, with lack of symptoms of gallbladder disease. The pathogenic mechanism (s) by which Gallstones (GS) form is generally agreed to be due to a) Alteration in the composition of bile b) Stasis c) Infection [3,4]. Gallstone disease (GSD) in patients with Diabetes mellitus (DM) is largely due to dyslipidaemia, leading to the alteration in the composition of bile. 
Impairment of gallbladder motility and contraction, as a result of hyperglycemia and diabetic autonomic neuropathy, also cause bile stasis and promote cholesterol GS crystal formation. They have also shown that fasting GB volumes were significantly increased in patients with multiple gallstones and that diabetic patients with autonomic neuropathy showed a decreased gallbladder emptying rate [5]. Hence the study is undertaken to determine prevalence of gall stones in diabetic patients and comparison of different parameters which affect gall stone formation.

\section{Objectives of the Study}

$>$ To determine the Gall bladder volume in diabetic patients.

$>$ Comparison of gall bladder volume in the study group with control group.

$>$ Correlation of gall bladder volume in diabetics with autonomic neuropathy and various parameters such as age, sex, body mass index, hyperlipidemia, duration of diabetes and glycemic control.

\section{Materials \& Methods}

The study was conducted on randomly selected 100 proven diabetic patients irrespective of age and age and sex matched 100 healthy controls enrolled in the Department of medicine, JJM Medical College, Davangere. An informed consent was taken from all the subjects in the study and control groups. The study protocol was approved by the ethical committee of the hospital. Study group consist of 100 diabetic patients (50 males and 50 females). Inclusion criteria : Diabetic patients with diabetic autonomic neuropathy diagnosed by standard tests, duration of diabetes more than 5 years, Functioning gallbladder, No evidence of gastrointestinal or hepatobiliary disease were included.

Exclusion criteria: The diabetic patients taking anti hypertensive drugs which interfere with Autonomic functions, Alcoholics, those with a history of major cardiac arrhythmias, Obese subjects (BMI > 25), Pregnant women, those with a past history of CVA were excluded from the Study.

Control group consist of age and sex matched 100 healthy volunteers (50 males and 50 females) without gastrointestinal, renal, and cardiac disease were recruited to the control group after taking informed consent. The selected patients were studied in detail with history and physical examination and relevant standard investigations.
Biochemical investigations conducted on the patients included blood glucose (fasting and postprandial), blood urea, serum creatinine, glycosylated haemoglobin, urinary albumin, microalbuminuria, serum lipid profile and liver function tests. An ultrasonographic evaluation of fasting gallbladder volume and postprandial gallbladder volume was done in all the subjects using a 3.5 or $5 \mathrm{MHz}$ transducer. The greatest length (L), greatest transverse width $(\mathrm{W})$, and antero posterior $(\mathrm{H})$ dimensions and presence of gallstones were recorded. The gall bladder volume was calculated by the ellipsoid Formula $=\pi \times$ L x W x H /6. Body mass index, Skinfold thickness, Waist circumference; Waist-Hip ratios were measured. Cardiac autonomic neuropathy in diabetic patients was assessed clinically by using simple noninvasive cardiovascular bedside tests, which included heart rate variation during squatting, heart rate variation during deep breathing, immediate heart rate response to standing, blood pressure response to standing and blood pressure response to sustained handgrip. The following autonomic function tests were performed, of the five tests the first two tests were used for sympathetic and later three for parasympathetic nervous system.

Resting pulse rate: The subjects / patients were asked to take rest for 10 minutes and radial pulse rate was recorded in supine position and expressed as beats / minute.

Resting blood pressure: The resting blood pressure was recorded in supine position using mercury sphygmomanometer and expressed in $\mathrm{mmHg}$

Valsalva ratio $=$ Longest $\mathrm{R}-\mathrm{R}$ interval after manoeuver /Shortest $\mathrm{R}$ - $\mathrm{R}$ interval during manoeuver

Evings protocol for assessment of Cardiac Autonomic Neuropathy Score (CAN)[6]

Heart rate response tests:

Heart rate response to valsalva Maneuver (VR)

Heart rate response to deep breathing (DBD)

Heart rate response to standing (PTI)

BP Response tests: Blood pressure response to Standing Blood pressure response to sustained hand grip(rise in diastolic BP)

Results interpreted as

Normal: All tests normal, or one borderline result. Mildly abnormal: One of the three heart rate tests abnormal, or 2 borderline (mild) 
Definitely abnormal: Two or more of the heart rate tests abnormal (moderate)

Severely abnormal: Two or more of the heart rate tests abnormal, plus one or both of the BP tests abnormal, or both borderline (severe) [7].

Statistical Methods: Descriptive statistical analysis has been carried out in the present study. Results on continuous measurements are presented on Mean \pm SD
(Min-Max) and results on categorical measurements are presented in Number (\%). Student $t$ test has been used to find the significance of study parameters on continuous scale between two groups, Inter group analysis on metric parameters.

Significant figures \# Suggestive of significance (P value: $0.05<\mathrm{P}<0.10)$, ${ }^{*}$ Moderately significant ( $\mathrm{P}$ value: $0.01<\mathrm{P} \leq 0.05)$, **Strongly significant ( $\mathrm{P}$ value: $\mathrm{P} \leq 0.01)$.

\section{Results}

A Case-Control Correlation study consisting of 100 controls and 100 Diabetic patients is udertaken to determine the Gall bladder volume. Since the number of Type 1 diabetics were not statistically significant in number=3 cases only, hence correlations of Type 1 diabetics with other parameters were not done separately.

The youngest patient studied was 21 years and oldest patient was 85 year old. The mean age of diabetics in study group was $57.2 \pm 13$ years \& in controls $55.7 \pm 17.61$ years. Majority of the patients are between the ages of $40-69 y$ yrs and controls between 40-60years.

Table-1: Mean gall bladder volume in study and control group.

\begin{tabular}{|c|c|c|c|c|}
\hline \multirow{2}{*}{ GB Volume(m) } & \multicolumn{2}{|c|}{ Controls } & \multicolumn{2}{c|}{ Cases } \\
\cline { 2 - 5 } & Males & Females & Males & Females \\
\hline Fasting & $13.0 \pm 3.45$ & $13.02 \pm 3.3$ & $23.09 \pm 7.3$ & $24.9 \pm 6.9$ \\
\hline Post prandial & $4.6 \pm 1.97$ & $5.3 \pm 1.83$ & $11.9 \pm 4.33$ & $11.8 \pm 4.49$ \\
\hline
\end{tabular}

Table-2: Prevalence of cardiac autonomic neuropathy (CAN) in control \& study group.

\begin{tabular}{|c|c|c|c|c|}
\hline \multirow{2}{*}{ CAN } & \multicolumn{2}{|c|}{ Controls } & \multicolumn{2}{c|}{ Cases } \\
\cline { 2 - 5 } & No & $\%$ & 10 & 10 \\
\hline Normal & 40 & 40 & 39 & 39 \\
\hline Mild & 34 & 34 & 21 & 21 \\
\hline Moderate & 16 & 16 & 30 & 30 \\
\hline Severe & 10 & 10 & $\mathbf{1 0 0}$ & $\mathbf{1 0 0}$ \\
\hline Total & $\mathbf{1 0 0}$ & $\mathbf{1 0 0}$ & No & \\
\hline
\end{tabular}

Table-3: Abnormal autonomic function tests observed in study and control groups.

\begin{tabular}{|c|c|c|c|c|c|c|c|c|}
\hline \multirow{2}{*}{$\begin{array}{c}\text { Autonomic } \\
\text { function tests }\end{array}$} & \multicolumn{4}{|c|}{ Controls } & \multicolumn{4}{c|}{ Cases } \\
\cline { 2 - 9 } & Males & $\%$ & Females & $\%$ & Males & \% & Females & $\%$ \\
\hline VR & 24 & 24 & 26 & 26 & 31 & 31 & 30 & 30 \\
\hline PTI & 16 & 16 & 14 & 14 & 20 & 20 & 28 & 28 \\
\hline DBD & 24 & 24 & 40 & 40 & 46 & 46 & 41 & 41 \\
\hline Fall in SBP & 8 & 8 & 10 & 10 & 21 & 21 & 29 & 29 \\
\hline Rise in DBP & 6 & 6 & 4 & 4 & 29 & 29 & 33 & 33 \\
\hline
\end{tabular}


Table-4: Comparison of Fasting GB volume with severity of Cardiac autonomic neuropathy.

\begin{tabular}{|c|c|c|c|c|}
\hline CAN & Normal & Mild & Moderate & Severe \\
\hline GB Volume $(\mathrm{ml})$ & 11.6 & 20.2 & 29.5 & 32.7 \\
\hline Controls & 10.3 & 13.5 & 15.3 & 17.1 \\
\hline
\end{tabular}

Table-5: Prevalence of gall stones in patients with autonomic neuropathy.

\begin{tabular}{|c|c|c|c|}
\hline SI No & & GS & \% \\
\hline 1 & Diabetics with AN $\mathrm{n}=90$ & 01 & 16.66 \\
\hline 2 & Diabetic swithout AN $\mathrm{n}=10$ & 05 & 8.33 \\
\hline 3 & Controls with AN $\mathrm{n}=60$ & 00 & 00 \\
\hline 4 & Controls without AN $\mathrm{n}=40$ & 00 \\
\hline
\end{tabular}

Table-6: Comparison of Age, BMI and WHR between controls and Cases.

\begin{tabular}{|c|c|c|c|}
\hline Demographic variables & Control group & Study group & P value \\
\hline Age in years & $55.72 \pm 17.61$ & $57.26 \pm 13.68$ & 0.557 \\
\hline BMI (kg/m2) & $20.51 \pm 1.56$ & $21.61 \pm 1.7$ & $<0.001$ \\
\hline WHR & $0.89 \pm 0.05$ & $0.93 \pm 0.05$ & $<0.001$ \\
\hline
\end{tabular}

Table-7: Comparison of Lipid parameters in study and control groups.

\begin{tabular}{|c|c|c|c|}
\hline Lipid parameters & Control group & Study group & P value \\
\hline LDL $(\mathrm{mg} / \mathrm{dl})$ & $91.72 \pm 8.3$ & $108.22 \pm 19.52$ & $<0.001$ \\
\hline Total cholesterol $(\mathrm{mg} / \mathrm{dl})$ & $160.16 \pm 10.45$ & $188.81 \pm 29.61$ & $<0.001$ \\
\hline Triglycerides $(\mathrm{mg} / \mathrm{dl})$ & $125.54 \pm 15.94$ & $192.42 \pm 63.42$ & $<0.001$ \\
\hline HDL $(\mathrm{mg} / \mathrm{dl})$ & $42.80 \pm 3.25$ & $36.02 \pm 5.83$ & $<0.001$ \\
\hline
\end{tabular}

Gall bladder volume was significantly increased in both fasting \& post prandial state in Diabetics compared to controls, which is statically significant ( $\mathrm{p}$ value $<0.001$ ). There was no difference in gall bladder volume between sexes in fasting $\&$ post prandial state in both cases \& controls. The motility defects of gall bladder disorders in diabetic patients leading to increased GB volume are due to decreased ejection fraction, decreased rate of ejection, and increased residual volume of the gall bladder.

Diabetics had autonomic system involvement to varying extent in $90 \%$ cases, compared to $60 \%$ controls by standard cardiac autonomic functions tests. $10 \%$ of diabetics had no autonomic involvement compared to $40 \%$ of controls. Diabetics had severe CAN to the extent of $30 \%$ compared to only $10 \%$ in controls. Mild to moderate autonomic involvement was seen in both cases \& controls to an equal extension.

Deep breathing difference (DBD) was the most common autonomic disturbance observed in both study and control groups, which was abnormal in $46 \%$ males and $41 \%$ in female study groups, $24 \%$ in males and $40 \%$ in female control group. Other parameters with varying extent i.e. $54 \%$ in males and $59 \%$ in female were observed in cases.

Gall bladder volume was positively correlated with CAN in diabetic \& controls. GB volume increase was graded upon the extent of CAN. Significant increase in GB volume was observed in diabetic patients with severe autonomic neuropathy. Gall bladder volume is directly related to the extent of autonomic involvement. Gall stones were present in $16 \%$ in study group as compared to $8 \%$ in control group. 
There was no significant difference between the demographic parameters with respect to Age. With respect to BMI and WHR, there was a significant difference between the cases \& controls, which was statistically significant $\mathrm{P}<0.001$.

$45 \%$ of males and $45 \%$ of females were having duration of diabetes between $5-10 y e a r s, 8 \%$ of males and $10 \%$ of females were having duration of diabetes between $10-15$ years, $2 \%$ of males were having duration of diabetes more than 15 years.

Mean values of LDL, Total Cholesterol and Triglycerides were higher in diabetics than compared control groups $(\mathrm{P}<0.001)$.

\section{Discussion}

The present study on Gall bladder volume in Diabetics is compared with various studies in literature for comparison of the data and the same has been analyzed. Various studies conducted in the past have shown a positive correlation between gall bladder disease and diabetes. The present study too showed the positive correlation between two. It has been confirmed that there is increased prevalence of gall bladder dysfunction among diabetics and diabetics tends to have larger gall bladder and reduced responsiveness to meals which might lead to development of Stasis of bile and development of complications like sludge, cholelithiasis and cholecystitis. Although exact pathophysiologic basis is not clear, motor abnormalities of gall bladder function is one of the proposed mechanism. These motor abnormalities could be due to larger size of gall bladder, impaired contractility due to vagal visceral neuropathy because of autonomic system involvement.

In the present study mean fasting gall bladder volume in control group was $13.05 \pm 3.3 \mathrm{ml}$ as compared to 24.01 $\pm 7.16 \mathrm{ml}$ in study group $(\mathrm{P}<0.001)$. Present study has shown increased fasting gallbladder volumes in diabetic patients as compared to healthy controls. The study conducted by AB Olokoba (Nigeria) [8], the fasting GB volume in diabetics was $27.6 \mathrm{ml}$ as compared to $24.3 \mathrm{ml}$ in controls, the reason for this variation is not explained.

GB volume has shown positive correlation with severity of autonomic neuropathy, Present study showed mean fasting GB volume in diabetics with $\mathrm{AN}$ was $32.7 \mathrm{ml}$ as compared to $11.6 \mathrm{ml}$ in diabetics without $\mathrm{AN}(\mathrm{P}<$ 0.001). S Singh et al[9] and Sharma MP et al.[10] showed similar findings in diabetic patients with autonomic neuropathy were having larger gall bladder volume, compared to diabetic patients without autonomic neuropathy.

Present study showed $16 \%$ prevalence of gall stone in study group as compared to $8 \%$ in control group.
Similar results were observed by other studies except study conducted by Chapman et al [11] where the prevalence of gall stones was $32 \%$, which can be due to ethnic variations in the incidence of gall stones.

In the present study GB volume has shown positive correlation with an increasing age correlation coefficient was $r=0.460$ in males and $r=0.328$ in females $(\mathrm{P}<0.001)$. AK Agarwal et al.[12] showed correlation coefficient in male diabetics was $r=0.423$ and in female diabetics $r=0.296$. Present study also showed positive correlation with age. As age advances, the gall bladder volume also increased. A.B. Olokoba et al.[8] showed positive correlation of GB volume and incidence of gall stones with age, Similar results were observed by Chapman BA et al.[11] present study is comparable with the above studies. But the presence of gall stones was not correlated with the gall bladder volume.

In the present study duration of diabetes showed positive correlation with gall bladder volume (less significant) Correlation coefficients in male study group was $\mathrm{r}=0.214(\mathrm{P}>0.05)$ and $\mathrm{r}=0.160$ in females $(\mathrm{P}>0.05)$. With $5-10$ years duration of diabetes mean GB volume was $24.9 \mathrm{ml}$ as compared to $24.5 \mathrm{ml}$ with duration of diabetes more than 10 years. Hence no significant correlation Güliter et al.[13] showed correlation of GB volume with duration of diabetes (r=0.212, $P<0.05)$. Mean ejection fraction of gallbladders in the study group was $48.48 \%$, whereas that of the control group was $56.32 \%$. Sharma MP et al.[10] showed patients with duration of diabetes more than 3 years fasting GB volume was $17.6 \pm 7.9 \mathrm{ml}$ as compared to diabetics with less than 3 years duration GB volume was $23.0 \pm 12.3 \mathrm{ml} \mathrm{P}$ (NS). All the three studies have not found any correlation of duration of Diabetes with gall bladder volume. Similarly present study also shows no correlation of GB volume with duration of Diabetes. 
BMI showed significant correlation with gall bladder volume, $\mathrm{r}=0.514$ in males and $\mathrm{r}=0.528$ in females $(\mathrm{P}<$ $0.001)$. The mean BMI in diabetic patients with gall stones was $21.8 \pm 1.53$ as compared to diabetics without gall stones $20.86 \pm 1.48$ corresponding GB volume was $24.3 \mathrm{ml}$ and $21.24 \mathrm{ml}$ respectively. Similar results were observed by A.k. Agarwal et al.[12], A B. Olokoba et al.[8]. They showed positive correlation with GB volume and incidence of gall stones with BMI. Mean $\mathrm{BMI}$ in diabetic patients with gall stones was $26.2 \pm 5.5$ as compared to diabetics without gall stones which was $25.7 \pm 6.7$ corresponding GB volume was $28.4 \pm 18.6 \mathrm{ml}$ and $27.4 \pm 14.4 \mathrm{ml}$ respectively $\mathrm{P}$ (NS). Hendel HW et al.[14] showed positive correlation of GB volume with BMI, The lithogenic index was $>1$ in all subjects and correlated with total fat mass $(\mathrm{P}=0.04)$. Similar results were observed by Chapman BA et al.[11]

WHR showed positive correlation with gall bladder volume $r=0.214$ in males $P$ value was not significant $(\mathrm{P}=0.136), \mathrm{r}=0.758$ in females $(\mathrm{P}<0.001)$, WHR was highly significant in female diabetics than compared to males, similar results were observed by Chapman B A et al.[11] and A K Agarwal et al.[12]

Gall bladder volume has showed positive correlation with LDL cholesterol levels, which was highly significant in male diabetics $r=0.415$ than compared to female diabetics, $\mathrm{r}=0.119(\mathrm{P}<0.05)$ that indicates risk of development of gall stones is significantly correlated with LDL Cholesterol levels in male diabetics. Similar results were observed by Chapman BA et al [11], A K Agarwal etal. [12] and Hendel HW et al. [14]. In the present study HDL levels showed negative correlation with GB volume in male diabetics $r=-0.299$ this indicates there is no correlation of GB volume with HDL levels in male diabetics. As compared to female diabetics $r=0.146$ indicates the absolute risk is very small. Similar findings were observed by Chapman BA et al.[11], AK Agarwal et al.[12] and Hendel HW et al.[14]

\section{Conclusion}

Ultrasonography is a simple and cost effective investigation routinely used in all diabetics for evidence of gall bladder diseases, which indirectly indicate involvement of autonomic neuropathy. Gall bladder disease is more prevalent among diabetics. Diabetics with autonomic neuropathy tend to have larger gall bladders with poor contraction in response to fatty meals, thus predisposing these patients to various forms of gall bladder diseases. In male type 2 diabetics, gallbladder volume significantly correlated with LDL cholesterol levels. In female type 2 diabetics, gallbladder volume significantly correlated with waist hip ratio. No correlation of gall bladder volume with glycemic control, microalbuminuria, duration of diabetes were observed. Clinical implication of this study is to help to detect the early gall bladder pathology and indirect involvement of autonomic neuropathy so that the morbidity and mortality due to diabetes mellitus is prevented to a greater extent.

\section{List of Abbreviations}

$\begin{array}{ll}\text { CAN } & \text { - Cardiac Autonomic Neuropathy } \\ \text { DM } & \text { - Diabetes Mellitus } \\ \text { FBS } & \text { - Fasting Blood Sugar } \\ \text { PPBS } & \text { - Post Prandial Blood Sugar } \\ \text { GB Vol } & \text { - Gall Bladder Volume } \\ \text { BMI } & \text { - Body Mass Index } \\ \text { WHR } & \text { - Waist Hip Ratio } \\ \text { TG } & \text { - Triglycerides } \\ \text { TC } & \text { - Total Cholesterol } \\ \text { HDL } & \text { - High Density Lipoprotein } \\ \text { VLDL } & \text { - Very Low Density Lipoprotein } \\ \text { MAU } & \text { - Microalbuminuria } \\ \text { GSD } & \text { - Gall Stone Disease } \\ \text { DAN } & \text { - Diabetic Autonomic Neuropathy } \\ \text { ANS } & \text { - Autonomic Nervous System } \\ \text { HTG } & \text { - Hypertriglyceridaemia } \\ \text { VR } & \text { - Valsalva Ratio } \\ \text { DBD } & \text { - Deep Breathing Difference } \\ \text { PTI } & \text { - Postural Tachycardia Index } \\ \text { WHO } & \text { - World Health Organization } \\ \end{array}$

Funding: Nil, Conflict of interest: None initiated, Permission from IRB: Yes

\section{References}

1. Vinik AI, Erbas T. Recognizing and treating diabetic autonomic neuropathy. Cleve Clin J Med. 2001 Nov;68 (11):928-30, 932, 934-44.

2. Jørgensen T. Prevalence of gallstones in a Danish population. Am J Epidemiol. 1987 Nov;126(5):912-21.

3. Robbins SL. pathogenesis of diseases. $5^{\text {th }}$ Edition, Philadelphia; WB Saunders; 1994.p. 884-888.

4. Paumgartner G, Sauerbruch T. Gallstones: pathogenesis. Lancet. 1991 Nov 2;338(8775):1117-21. 
5. Hahm JS, Park JY, Park KG, Ahn YH, Lee MH, Park KN. Gallbladder motility in diabetes mellitus using real time ultrasonography. Am J Gastroenterol. 1996 Nov; 91(11):2391-4.

6. Ewing D. J. Autonomic function testing (clinical)Michael Poon's Shrine of Neurology. 1985,1988 in www.Autonomic function testing. html. (Accessed on 4/1/03).

7. American Diabetes Association Diagnosis and Classification of Diabetes Mellitus Diabetes Care January 2010; 33:S62-S69.

8. A.B. Olokoba, B J Bojuwoye, L.B.Olokoba, K.W.Whab, K. T. Braimoh, A. K. Inikor et.al. The relationship between gall bladder disease and gallbladder wall thickness African scientist Dec 31, 2006; 7(4):171-176.

9. S Singh, $\mathrm{R}$ Chander A Singh, S Mann Ultrasonographic Evaluation Of Gall Bladder Diseases In Diabetes Mellitus Type 2 Ind J Radiol Imag 2006;16:4:505-508.
10. Sharma MP, Saraya A, Anand AC, Karmarkar MG. Gall bladder dysmotility in diabetes mellitus--an ultrasound study. Trop Gastroenterol. 1995 Jul-Sep; 16(3):13-8.

11. Chapman BA, Chapman TM, Frampton CM, Chisholm RJ, Allan RB, Wilson IR, Burt MJ. Gallbladder volume: comparison of diabetics and controls. Dig Dis Sci. 1998 Feb;43(2):344-8.

12. Agarwal AK, Miglani S, Singla S, Garg U, Dudeja RK, Goel A. Ultrasonographic evaluation of gallbladder volume in diabetics. J Assoc Physicians India. 2004 Dec; 52:962-5.

13. Güliter, Sefa, Ylmaz, Sevda, Karakan, Tarka. Evaluation of Gallbladder Volume and Motility in NonInsulin-Dependent Diabetes Mellitus Patients Using Real-Time Ultrasonography Journal of Clinical Gastroenterology. Oct 2003; 37(4):288-291.

14. Hendel HW, Højgaard L, Andersen T, Pedersen BH, Paloheimo LI, Rehfeld JF, Gotfredsen A, Rasmussen MH. Fasting gall bladder volume and lithogenicity in relation to glucose tolerance, total and intra-abdominal fat masses in obese non-diabetic subjects. Int $\mathrm{J}$ Obes Relat Metab Disord. 1998 Apr;22(4):294-302.

\section{How to cite this article?}

Kotresh Doddamane, Adarsh V B, Deepak Kumar V. A correlative study of autonomic neuropathy and gall bladder volume in patients with diabetes mellitus. Int J Med Res Rev 2016;4(9):1559-1565.doi:10.17511/ijmrr.2016.i09.07. 